\title{
Experiences of the Insured and Non-Insured of the NHIS in Accessing Health-care in Tema, Ghana
}

\author{
Robert Teye Plahar \\ Jiangsu University, School of Management \\ 301 Xuefu Road, Zhenjiang, 202013 \\ P.R. China \\ E-mail: rplahar@hotmail.com
}

Dai Baozhen (Corresponding author)

Jiangsu University, School of Management, Department of Health Policy and Management

301 Xuefu Road, Zhenjiang, 202013

P.R. China

E-mail: hixiaodai@126.com

\author{
Abubakar Saddiqque \\ Jiangsu University, School of Management \\ 301 Xuefu Road, Zhenjiang, 202013 \\ P.R. China \\ E-mail: lanre902@outlook.com \\ Sandra Asantewaa Mensah \\ Shanghai Jiao Tong University \\ 800 Dongchuan Road, Shanghai \\ P. R. China \\ E-mail: sandymens.gh@yahoo.com
}


Received: Dec. 24, 2019 Accepted: Jan. 17, 2020 Online published: Feb. 3, 2020

doi:10.5296/jpag.v10i1.16130

URL: https://doi.org/10.5296/jpag.v10i1.16130

\begin{abstract}
The study analyzes the impacts emanating from the National Health Insurance Scheme in its attempt to ensuring that Ghanaians can access quality and affordable health-care. The study focuses on three hospitals; CJ Medical Centre, Sakumono Community Hospital and Tema General Hospital in the Tema, Ghana.

To realize the objectives, the study applies a mixed approach to collecting and analyzing data. An interview guide and semi-structured criteria are used in the collection of data. The collected data included qualitative and quantitative data and were analyzed using color coding based on emerging themes and SPSS 18 respectively. The study was able to establish that, comparatively, people insured by the NHIS have enhanced accessibility when it comes to health-care, than the non-insured. The insured enjoy benefits from the Scheme and together with their children below 18 years enjoy free laboratory, OPD dispensary and consultation services, and some surgical procedures in both private and public hospitals.

On the contrary, the non-insured have no option other than paying for the same services when in need of medical attention. However, non-insured who have cash at the ready are readily attended to while those enrolled on the NHIS may have to wait a bit longer to be served.

Recommendations include authorities ensuring claims are settled promptly, expansion of number of drugs and conditions covered by the NHIS, reduction in premiums and measures to ensure health workers are not biased against the insured.
\end{abstract}

Keywords: national hospital insurance scheme, insured, non-insured, Ghana, health-care, hospitals

\title{
1. Introduction
}

Good health is undeniably among the leading human prerequisites for living a quality and comfortable life. Consequently, it is of crucial necessity to grant human health utmost prioritization since an unhealthy population implies that a nation will be stagnated across a majority of its existential scopes; that is economically, politically, and socially. Ghana, just like most developing nations, is primarily characterized by a struggling health care system. However, the Ghanaian government, together with other local, as well as international players, are recording tremendous levels of partnership in the attempt to improve the country's health care system. Therefore, one of the chief initiatives geared toward the attainment of universal and affordable health to the Ghanaian citizens is the National Health Insurance Scheme (NHIS).

The NHIS covers $95 \%$ of health-care services including maternal health services, and all health providers with certification are covered (Witter and Garshong 2009; Nguyen et al. 2011). $95 \%$ of the most common disease conditions reported in health-care facilities in Ghana 
are covered under the scheme (Gobah and Zhang, 2011). The NHIS was conceived as a successor to the "cash and carry" system which was proven to be greatly unfavourable to the poor.

Although there has been a number of studies evaluating the effect of health insurance on the use of general health care outpatient and in-patient (Giedion et al. 2013) and also some on its impact on maternal health-care, there is limited empirical evidence on its direct influence on accessing and utilizing of health-care. The objective of this study is to provide an unbiased in-depth comparative analysis on the experiences in accessing and utilizing health-care by both the insured and non-insured.

\section{Literature Review}

\subsection{The Concept of National Health Insurance Scheme}

Certified evidence underscores the veracity that the introduction of health insurance more so in developing countries such as Ghana is a significant endeavor towards the improvement of individuals' accessibility to health-care (Nolan and Turbat, 1995). Therefore, several developing nations, among them, the state of Ghana, have opted to embrace and implement varying models of health insurance with the focal point of offering their people affordable, reliable, and universal health. However, in as much as many nations are keen to prioritize the provision of quality and affordable health-care, the financing of health-care services has proved to be a major impediment to the most government in the effort of these governments taking the forefront as the agents of health systems. According to a World Health Organization study carried out in 2009, health-care expenditure is mainly composed of 85 percent of out of pocket payments (Chalkidou et al. 2009). The study also revealed that in the instance poor individuals have to pay for care, they may opt not to seek medication and thus either become more impoverished or heavily indebted.

Additionally, nations that spend limited funds on health-care, most of which are in the developing world, are typically characterized by deplorable health-care conditions (Carrin et al. 2005). These countries, with Ghana as the perfect example, thus have a low life expectancy level. To minimize out of pocket payments as well as to improve the accessibility of individuals to health care, the adoption and application of health insurance is the ultimate remedy. In the year 2003, the Ghanaian government founded the National Health Insurance Scheme, whose establishment was mainly in line with the millennium development agenda (Nolan and Turbat, 1995). The focal point for the establishment of the NHIS was and continues to be making health-care not only affordable but as well as more accessible to the citizens of Ghana.

Most Ghanaians live below a dollar per day. As a result, the government of Ghana, in an attempt to eradicate poverty, spends more resources on the underprivileged citizens in society. To provide opportunities to these needy persons, the government of Ghana provides the much-needed support coupled with financial assistance so that they may be able to live relatively comfortable lives (Berk and Monheit, 2001). Essentially, the vital need for eradicating poverty is among the leading reasons as to why most developing nations are 
mainly characterized by low spending in health systems. Importantly, the Ghanaian National Health Insurance Scheme that has been in operation for almost two decades now is chiefly a kind of a social health-care insurance which has embraced prepayment method based on financial contributions for health-care as elaborated in the resolution adopted by the World Health Organization in the year 2005 (Carrin et al. 2005).

The prepaid system is designed to collect funds using both insurance and tax contributions that ultimately enable Ghanaians to have access to health-care services that are needed. The strategy is undeniably very pivotal due to the fact that the poor are now immune to stress and despair arising from health-care financial need (Creese, 1991). This has mostly been made possible through the application of a cross-subsidizing or reduced out of pocket spending. More so, to widen the local sources of funding of the health-care sector of most nations, the International Monetary Fund, the World Health Organization as well as other donor organizations occasionally offer financial assistance to the developing countries mainly to aid in the realization of quality health-care to the underprivileged (Berk and Monheit, 2001).

Nonetheless, in as much as the Ghanaian National Health Insurance Scheme is focused on eradicating health care accessibility and affordability, it has not been immune to criticism. Several people and institutions such as the civil society and the media have cried foul of the Scheme claiming its immersed in discriminatory practices as well as the claim of the Scheme being used by politicians as a money milking bag. On the other hand, also, the Scheme has received numerous applauds since several people have acknowledged the evident beneficence of the Scheme since it has extinguished the despair previously endured by most Ghanaians since they no longer need to part away with lots of cash in seeking health-care (Nolan and Turbat, 1995).

\subsection{Reasons for the Establishment of the NHIS}

As summarily stated above, the chief reason for the establishment of the NHIS was to pursue improvement in the overall quality of primary health-care services for all the citizens of Ghana and mainly the vulnerable and more impoverished, putting into consideration access and utilization. The introduction of the Scheme essentially lifted the heavy burden the people of Ghana having to use the cash and carry system face. To the poor, the NHIS was the much-craved system to pull them out of their misery since it relatively guaranteed them social protection due to its potential to assist as far as their health-care expenditures are concerned.

Five years after the introduction of the Scheme, the Ghanaian government carried out a Nationwide Assessment to determine the number of its citizens using the Scheme. In the evaluation, the government established that more than 40 percent of its citizens had not subscribed to the Scheme, whereas for the 36 percent who had ever registered, mainly failed to renew their cards once their membership expired (Berk and Monheit, 2001). The prevalence of this trend was catalyzed primarily by several factors, some of which include the low standards of health-care services, verbal abusing of clients, delay in the time of waiting in health-care facilities, among other factors.

Besides, other major factors affecting the National Health Insurance Scheme revolve around 
the general public. Elaborately, some of the factors or the challenges that mainly confront the operations and functionality of the National Health Insurance Scheme are interruptions in the reimbursement of claims and exponential rise in the utilization of health-care services and facilities by the insured clients while lacking a corresponding increase in the number of health-care facilities and the staff in general (Nolan and Turbat, 1995). Also, other challenges are the embezzlement of funds by the scheme authorities as well as fraud and irregularities.

Regardless of the above issues, it is indeed incontestable to assert that the accessibility of health-care had recorded a significant increment since the year 2003 when the Scheme was established (Chalkidou et al. 2009). Notably, however, is the fact that the conduct of both the insured and the uninsured clients of the National Health Insurance Scheme as far as the accessibility of health-care services is concerned is mainly ascribed to either their present or past experiences that they encountered at the health-care facilities in their pursuit of health-care services. Ghanaians lacking insurance cover are submerged in dire challenges of the need to every time make high payments when accessing health-care services (Berk and Monheit, 2001). Also, uninsured Ghanaian citizens are highly vulnerable to losing their lives since they are unable to afford health services.

However, for the insured, it is a common scenario that a majority of these people are unable to access health-care primarily due to the interruptions emanating from the provision of cards bearing the names of the members of the Scheme in health-care facilities. As a result, most insured clients have more preference for seeking health-care services from private health institutions where they are willing to incur high charges but receive quality health-care services.

\subsection{The Role Played by the NHIS towards Ghana's Health-care Accessibility}

Those who have access to the National Health Insurance Scheme can go for treatment without necessarily having money. Another benefit is that children (under 18 years) of parents who are subscribed could access health care for free (Carrin et al. 2005). The other benefits of subscribers are that they can have access to essential drugs even if they lack money, women who are pregnant can also attend hospitals without paying, they ensure their health against ill-health, and they can visit the anti-natal and give birth at the hospital without paying anything.

Ideally, those with NHIS have better access when it comes to health care facilities compared to their counterparts who are non-subscribers. Attempts aimed at pooling risks and resources towards the creation of a health insurance scheme, such as the NHIS, enable nations to ensure better access and provide risk protection to poor households against the cost of illness (Nolan and Turbat, 1995). However, it is very important to note the existence of many challenges that are associated with the operation of the Scheme. That is why there is a tendency for many people to believe that the NHIS subscribers have no better access than non-subscribers. 


\section{Methodology}

\subsection{Research Design}

The research adopts an approach of mixed methods by using a combination of quantitative and qualitative research methods in the collation and analysis of its data. The mixed methods applied in doing research can be termed as a research design that contains both the inquiry method and the philosophical assumptions as guidelines of its operations. The adoption of the mixed-method approach, therefore, enabled the study to have a much comprehensive plan in answering the research questions together with the usage of various methods to offset and supplement each others weaknesses.

Structured survey questionnaires and also interviews were used in the collection of information from respondents from three hospitals. The hospitals were CJ Medical Centre, Sakumono Community Hospital and Tema General Hospital. The questionnaires were divided into four main sections which dealt with demography of the respondents, awareness of the NHIS, motivational factors for joining the NHIS and their experiences with accessing health-care. A total of 200 questionnaires were distributed out of which 170 were returned. Mode of delivery was mainly by hand and all of the interviews were done on site.

\subsection{Data Analysis and Presentation of Findings}

\subsubsection{Demography of Respondents}

Table 1.

\begin{tabular}{l|l|l|l}
\hline & Gender & Frequency & Percentage \\
\hline Insured & Males & 50 & 29.4 \\
\hline Non-insured & Females & 65 & 38.2 \\
\hline & Males & 30 & 17.6 \\
\hline Total & Females & 25 & 14.7 \\
\hline Insured & & $\mathbf{1 7 0}$ & $\mathbf{1 0 0}$ \\
\hline Non-insured & Age & & \\
\hline & $18-30$ & 20 & 11.8 \\
\hline Total & $30-45$ & 95 & 55.9 \\
\hline & $18-30$ & 45 & 26.5 \\
\hline Insured & $30-45$ & 10 & 5.9 \\
\hline & & $\mathbf{1 7 0}$ & $\mathbf{1 0 0}$ \\
\hline Non-insured & Marital Status & & \\
\hline & Single & 35 & 20.6 \\
\hline Total & Married & 80 & 47.1 \\
\hline
\end{tabular}

The number of participants for the study was a total of 170 respondents. Majority of the respondents were women i.e 90 representing 53\% whilst the men were 80 representing $47 \%$. From the table, it is clear that the highest percentage of insured is women representing $38.3 \%$.

The respondents ages ranged from 18-45 with the majority of them being in the 30-45 age bracket $(61.8 \%)$. This may point to the fact that most older people frequently seek health-care 
as compared to younger people. Also, it was noted that those in the older age bracket had a very high insurance rate (55.9\%). This was relatively much higher than the 18-30 age bracket which recorded an insurance rate of just $11.8 \%$.

Majority of the respondents were married. Out of the 170 respondents who partook in the interview, $55.9 \%$ were married whilst $44.1 \%$ were single. Most of the married respondents were enrolled on the NHIS $(47.1 \%)$ with just a few of them being non-insured. This hints at a strong link between being married and being enrolled on the NHIS.

\subsubsection{Factors That Motivate People to Join the Scheme}

Table 2.

\begin{tabular}{l|l|l|l}
\hline Motivational Factors & Frequency & Mean & $\begin{array}{l}\text { Std. } \\
\text { Devn. }\end{array}$ \\
\hline Affordable health insurance premium & $81 \%$ & $5.65(3)$ & 0.0121 \\
\hline Access to free drugs & $91 \%$ & $5.81(1)$ & 0.072 \\
\hline Social security against unforeseen health problems & $89 \%$ & $5.7(2)$ & 0.025 \\
\hline $\begin{array}{l}\text { Encouragement by friends, family members, and } \\
\text { Colleagues }\end{array}$ & $79 \%$ & $5.25(4)$ & 0.084 \\
\hline
\end{tabular}

From the table depicted above, respondents agreed that all the factors stated above motivate people to join the National Health Insurance Scheme. However, the majority of the respondents agreed that access to free drugs is the strong arsenal that motivates people to join the Scheme. It had a mean rating of (5.81) representing 91\%. Another factor, according to the respondents, was that, social security against unforeseen health, which accounted for a mean rating of (5.7) representing 89\%. The respondents supported their argument with the fact that sickness emerges at any time and would not inform when and where it will strike. Therefore, with the National Health Insurance Scheme (NHIS), individuals would not be agitated since insurance is there for assistance.

They further agreed that the affordable health insurance premium is a significant factor that motivates people to join the Scheme with a mean rating of (5.65) representing $81 \%$. At times, individuals find it tedious to get money for health care; when this happens, since the NHIS subscriber has contributed something little as premium, the sick would be able to visit the hospital. The least of the factors according to the respondents that motivate people to join the Scheme is an encouragement by friends, family members, and colleagues. It had a mean rating of (5.25) with a percentage of $79 \%$. 


\section{Macrothink

3.2.3 Reasons for not Enrolling on the Scheme

Table 3.

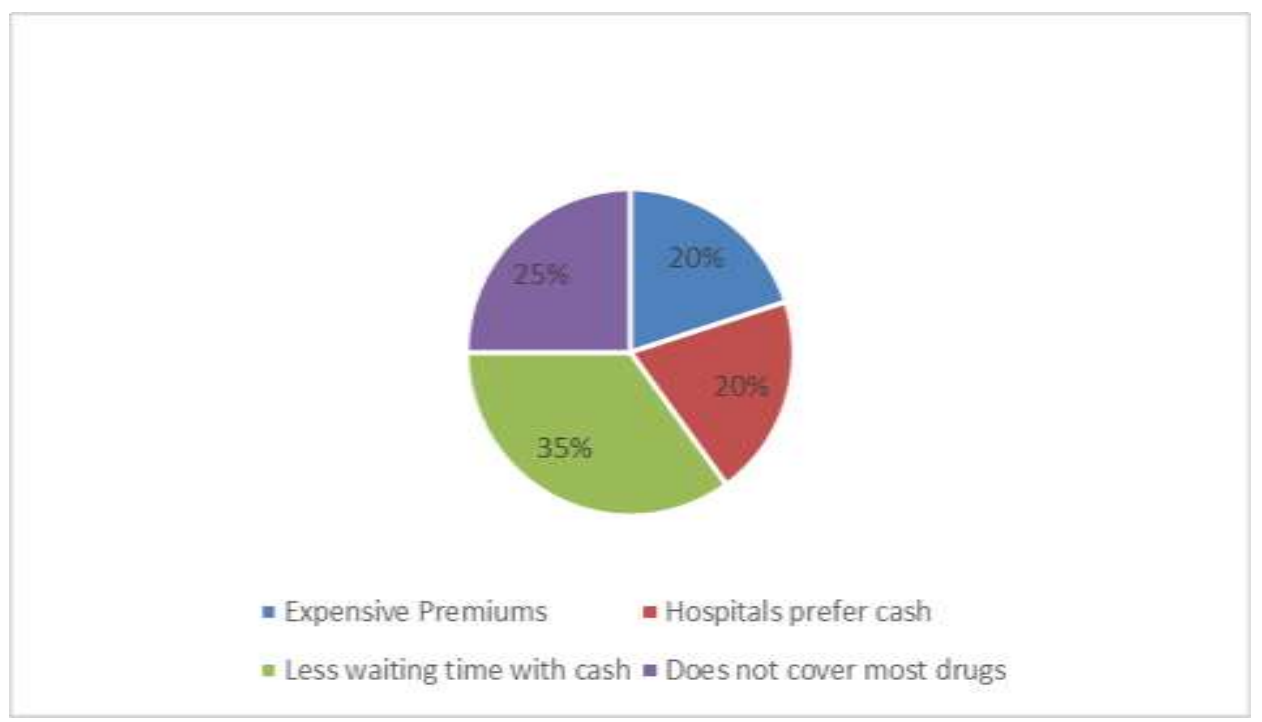

The non-insured gave a variety of reasons why they did not feel the need to subscribe to the NHIS. Chief among these reasons was the notion that wielding cash meant having to wait for a lesser period and being attended to quickly. $35 \%$ of them mentioned that as their primary reason for being uninsured. They did not see why they should pay to be enrolled on the NHIS and have to be delayed at the health-centres because of that.

The next major reason was the fact that most drugs and procedures were not covered by the NHIS. 25\% of respondents cited this as their primary reason for not joining the NHIS since according to them health-care seekers ended up paying more money for various drugs all the time irrespective of whether they were insured or not.

Some of the respondents also mentioned their main reason for not joining the NHIS was expensive premiums. Respondents were of the view that the premiums were far too costly. They preferred to save the little money they had and most tend to seek unorthodox medicine when they need medical attention and only find their way to hospitals as a last resort. This was the view of $20 \%$ of respondents. This point in particular is very interesting since in sharp contrast, affordable premiums was also a factor that motivated people to join the NHIS.

The rest cited the fact that most of the hospitals preferred cash. This has a strong connection to the first two reasons and reinforces the notion of "cash is king" when seeking medical attention or health-care. 


\subsection{Inequalities in Accessing Health Care}

Table 4.

\begin{tabular}{|l|l|l|l|l|}
\hline & Yes & Percentage & No & Percentage \\
\hline $\begin{array}{l}\text { Insured have easier access to } \\
\text { health-care than non-insured }\end{array}$ & 128 & $\mathbf{7 5 . 2 9}$ & 42 & $\mathbf{2 4 . 7 1}$ \\
\hline $\begin{array}{l}\text { Non-insured have difficulty in } \\
\text { accessing health-care }\end{array}$ & 110 & $\mathbf{6 4 . 7 1}$ & 60 & $\mathbf{3 5 . 2 9}$ \\
\hline $\begin{array}{l}\text { Insured pay extra money for } \\
\text { health services }\end{array}$ & 60 & $\mathbf{3 5 . 2 9}$ & 110 & $\mathbf{6 4 . 7 1}$ \\
\hline $\begin{array}{l}\text { Non-insured who have cash are } \\
\text { attended to promptly than } \\
\text { insured }\end{array}$ & 127 & $\mathbf{7 4 . 7 1}$ & 43 & $\mathbf{2 5 . 2 9}$ \\
\hline $\begin{array}{l}\text { Non-insured pay significantly } \\
\text { more money than insured }\end{array}$ & 95 & $\mathbf{5 5 . 8 8}$ & 75 & $\mathbf{4 4 . 1 6}$ \\
\hline
\end{tabular}

The data in the table above strongly indicates that people who are insured with the NHIS enjoy significant benefits as compared to those who are not enrolled on the scheme. They have the advantage of walking into any health facility at anytime even if they have no money at hand. However, it can clearly be seen that ultimately patients who have cash at hand are given the utmost priority hence non-insured who have the financial backing are more likely to be attended to rapidly. The data also shows that about $44.16 \%$ of the respondents believe the difference between money paid by the non-insured and insured in the end is not so big. This was further clarified in the interviews as being a result of non-availability of drugs at the hospitals or the drugs not being on the NHIS list hence insured and non-insured both end up paying for them.

Several aspects merge to jointly impact the accessibility and utilization of health insurance schemes across many nations. These factors mostly seem to enlighten the conduct of individuals seeking health-care (Berk and Monheit, 2001). The type of practices induced into the health seekers by these factors perpetually dictates the achievement or the failure of the schemes. The accomplishment of a given NHIS is primarily analyzed basing on the equity of its financing, the beneficiaries, its political acceptability, the costs of administration, and the efficiency effect of the Scheme (Chalkidou et al. 2009). Correspondingly, the decision to settle on a given health insurance plan as well as the extent of involving an individual's household are chiefly piloted by two prime determinants. These are the personnel and the features of the plan. The scope of the personnel includes the community features and the household of the person making a choice. NHIS subscribers have several advantages and benefits that the uninsured lack. Regarding service delivery speed, from the study, it is evident that NHIS non-insured cash holders are prioritized at the expense of the NHIS subscribers in receiving health-care (Nolan and Turbat, 1995).

\subsection{Health Attendants Attitude Towards the Health Seekers}

To further analyze the scope of accessibility to health-care by both the non-insured and the insured of NHIS, the research opted to grill heath attendants' attitudes within the health-care facilities concerning the two groups when seeking health-care. 
It was realized that the health staff appeared more lenient and patient to the uninsured who had cash than towards the card holders. For instance, $46 \%$ of NHIS subscribers claimed that the health attendants were at least patient with them, but the rest $54 \%$ said the health staff were very impatient towards them. However, for the uninsured, while as much as $84 \%$ praised the attendants for at least being patient, only $16 \%$ said they experienced any impatience.

Other than the claimed cause as to why some health seekers experience hostility from health staff, the other purpose may be the intensity as well as nature of a health seeker's illness. Hence, it could probably revolve around the notion that these emanating hostilities and friendliness levels of differentials may be due to the inclination that might have made most of the insured clients to seek treatment on illnesses deemed to be minor by the health staff and as such unnecessary to go visiting the health-care facilities. The prevailing perception was that once they had insurance they tended to visit the hospital frequently irrespective of how minor or little the sickness might be. This was in sharp contrast to the uninsured who could only afford to go to the hospital if only they felt they had strong reason to. This may account for the differential on the level of attitudes of the health staff attitudes towards the two categories of health seekers.

\subsection{Health Staff Response Towards the Holders of NHIS Cards}

$23 \%$ of the NHIS cardholders claimed a forceful requirement of the payment of additional cash, whereas the $77 \%$ paid no additional money. When those who paid extra money were asked to say what the money they paid was meant for, majority of the respondents (85\%) said the money was intended to cover the cost of extra medicines that were not covered by the NHIA approved drug list. Asked further if the respondents were able to access all the drugs prescribed for them at the health facilities, concerning the NHIS subscribers, $71 \%$ of the respondents responded in the affirmative with the rest $29 \%$ responding in the negative.

Besides, the clients who were unable to obtain all the drugs prescribed to them were requested to state the reasons. Among the respondents, therefore, $65.5 \%$ of them claimed that the drugs they were unable to get as prescribed were mainly lacking in the NHIS drug list. Consequently, they had to pay for the same drugs. The remaining respondents equally claimed the dispensaries they visited lacked the drugs. On the other hand, $81 \%$ of the uninsured respondents acknowledged being able to buy the entirety of drugs at the dispensaries as prescribed to them. For the remaining 19\% who were unable to acquire all the prescribed drugs, they indicated that the drugs were mainly out of stock at the dispensary store. However, there is a lack of clarity on making an ultimate decision on whether the existing discrepancy between cash holders and NHIS cardholders is due to the preference for cash and not cards by the dispensary attendants.

\subsection{The Prime Impediments in Health-care Services Access and Usage by Insured and} Non-Insured Ghanaian Clients

As clarified by the study's findings as well as other studies, in several ways, NHIS subscription has more advantages to the several low-income people living in poverty-stricken 
nations. Unfortunately, most of these individuals are unable to join complementary health schemes. Poverty is the chief reason for their inability to join health schemes (Chalkidou et al. 2009). Therefore, while individuals may have a sincere craving to join these schemes, their incapability of making premium payments because of poverty thwarts them. Also, some other leading reasons mostly revolve around the perception than NHIS cardholders are usually left unattended to for long hours while seeking medication in health facilities as well as the impression that the Scheme covers solely mainly cheaper drugs that clients can easily purchase without necessarily trying NHIS subscription.

Moreover, other perceived hindrances include being too expensive for the ordinary health seeker, the Scheme covers only simple surgical problems, Health facilities prefer cash and compared to NHIS, some people do not get sick often, people prefer to use traditional systems rather than orthodox method for cure, unavailability of health facilities in their communities and Health facilities are too far from them (Nolan and Turbat, 1995). Critically considering the views expressed above, it is undeniably evident that poverty solidly standouts as the primary basis for most people's inability to join NHIS. More so, though some individuals may be unable to cater for the initial registration fees necessary for one's membership approval, several others at the expiry of their membership are unable to renew the membership.

The view that only trivial surgical operations and cheap drugs are under the health insurance scheme coverage are part of the factors that deviate people's interest to join the Scheme. Importantly also to note is the view that health staffs have much preference to first attend to cash holders than the cardholders that essentially culminates into time wastage by the cardholders since they are forced to wait for several hours compared to the cash holders (Creese, 1995). The findings of this study confirm several results of many studies. Chief among them is the fact that low income is a substantial barrier to the utilization of modern primary medical facilities, even when publicly provided as well as the veracity that in the developing countries, the poor have less access to health services (Berk and Monheit, 2001).

The findings moreover point and affirm the fact that the NHIS cover provides limited services. For instance, it reinforces the fact that the NHIS covers outpatient services that include diagnostic operations and testing, for example, hernia repairs. Several inpatient services such as surgeries and specialist care, as well as general ward hospital accommodation. Oral health treatment is equally provided, including Caesarean deliveries and all care services revolving around maternity. Emergency care services are also covered as well as the entirety of the drugs that are primarily established by the National Health Insurance Scheme List of Medicines (World Bank, 1988).

Nonetheless, the NHIS package fails to include several costly procedures, for example, some types of surgeries, dialysis, organ transplants, the treatment of cancer (apart from cervical and breast cancer). Other services that are also not incorporated include certain high-profile substances, for example, HIV ARVs (Nolan and Turbat, 1995). Other subjects appeared that mainly revolve around the administration and management of the NHIS that were regarded as part of the agents increasing the inaccessibility and underutilization of the Scheme by the 
health seekers. The major barriers to NHIS mainly revolve around the inability of the scheme managers to reimburse the service providers in time, insufficient supervision, overcharging invoices, poor record-keeping and poor filling of forms for claims, an inadequate supply of essential drugs to the public health facilities (Carrin et al. 2005). These factors were regarded to be converging together to act as even much more impediments to the NHIS attaining smooth running and operation. Thus, these factors in several ways, seem to discourage possible and discontented subscribers away from the access and utilization of NHIS.

\section{Conclusion}

The study collected showed that although there are many perceived benefits of enrolling on the National Health Insurance Scheme, the situation on the ground actually tells a different story altogether. It was found out that "cash is king", hence uninsured patients who were ready to dole out cash received quicker treatment than those who were insured. In fact a few respondents even went as far as to complain that sometimes being insured with the NHIS meant you got served last and even in extreme cases treated with very little impatience by health workers.

However, it was also noted that being on the scheme had its' own advantages such as being able to walk into any health facility at any time regardless of your financial situation. Also, the insured praised the NHIS since in situations where there was an emergency, time wasn't wasted in trying to raise funds for health-care. Other benefits mentioned were free health-care for maternal health and also the fact that children of the insured who were under 18 years could enjoy free health-care. This is in sharp contrast to the uninsured who have no choice but to always pay up when they are in need of medical attention.

Respondents who were not enrolled on the NHIS when asked why gave a variety of reasons with the majority of them claiming they were more likely to be attended to quickly by health workers if they paid cash. Some also mentioned the NHIS does not cover many drugs hence they didn't see the need to "waste" money on it and others complained about the premium payment being to expensive for them to afford.

All in all, the study revealed that the NHIS was perceived by many people to be a laudable policy but it's actual implementation had caused the difference in opinion on if one should join it or not. This decision is also reinforced by the personal experiences of the people which in turn determines if they enroll on the scheme or take their chances with being uninsured.

\section{Recommendations}

To sum up, in the attempt to improve access to health-care services in Ghana as well as improve the functioning capacity of the NHIS, measures to lower the relatively high cost of registration as well as the premium rates established by the Scheme to increase the possible NHIS subscription numbers are of utmost importance. Also, there is the need for the NHIS to broaden its list of drugs to include expensive drugs and the supply of critical drugs/medicines to the health institutions be increased to get rid of the scenario where health facilities run out of drugs. Serious medical conditions which are very expensive should also be catered for by the NHIS. Authorities also have to ensure they are no delays in insurance claims to the 
health-care providers and health workers need to be enlightened on the need to treat people who are insured on the scheme with maximum professionalism. The National Health Insurance Scheme is undeniably a significant step towards the easy accessibility of health-care as well as the realization of quality and affordable health-care.

\section{References}

Agyepong, I. A., \& Adjei, S. (2008). Public social policy development and implementation: a case study of the Ghana National Health Insurance scheme. Health policy and planning, 23(2), 150-160. https://doi.org/10.1093/heapol/czn002

Asfaw, A., \& Von Braun, J. (2004). Can community health insurance schemes shield the poor against the downside health effects of economic reforms? The case of rural Ethiopia. Health policy, 70(1), 97-108. https://doi.org/10.1016/j.healthpol.2004.02.005

Beaulieu, D. (2001). The Longer View: Moving Toward Population Health in the Federal Sector. In Advancing Federal Sector Health Care (pp. 5-16). Springer, New York, NY. https://doi.org/10.1007/978-1-4757-3439-3_1

Berk, M. L., \& Monheit, A. (2001). The Concentration of Health Care Expenditures, Revisited. Health Affairs, 20(2), 9-18. https://doi.org/10.1377/hlthaff.20.2.9

Blanchet, N. J., Fink, G., \& Osei-Akoto, I. (2012). The effect of Ghana's National Health Insurance Scheme on health care utilisation. Ghana medical journal, 46(2), 76-84.

Brugiavini, A., \& Pace, N. (2016). Extending health insurance in Ghana: effects of the National Health Insurance Scheme on maternity care. Health economics review, 6(1), 7. https://doi.org/10.1186/s13561-016-0083-9

Carrin, G., Waelkens, M. P., \& Criel, B. (2005). Community - based health insurance in developing countries: a study of its contribution to the performance of health financing systems. Tropical medicine \& international health, 10(8), 799-811. https://doi.org/10.1111/j.1365-3156.2005.01455.x

Chalkidou, K., Tunis, S., Lopert, R., Rochaix, L., Sawicki, P. T., Nasser, M., \& Xerri, B. (2009). Comparative effectiveness research and evidence - based health policy: experience from four countries. The Milbank Quarterly, 87(2), 339-367. https://doi.org/10.1111/j.1468-0009.2009.00560.x

Creese, A. L. (1991). User charges for health care: a review of recent experience. Health policy and planning, 6(4), 309-319. https://doi.org/10.1093/heapol/6.4.309

Fuseini, S., \& Anthony, S. (2018). To: Plos One Knowledge, experiences and perceptions of the Ghana National Health Insurance Scheme in three districts. bioRxiv, 490359. https://doi.org/10.1101/490359

Geller, R. J. (2001). The first year of Health Improvement Programmes; views from directors of public health. Journal of Public Health, 23(1), 57-64. https://doi.org/10.1093/pubmed/23.1.57 
History of Ghana. (2006). Wikipedia. Retrieved from: http://en.wikipedia.org/w/index

Jehu-Appiah, C., Aryeetey, G., Spaan, E., De Hoop, T., Agyepong, I., \& Baltussen, R. (2011). Equity aspects of the National Health Insurance Scheme in Ghana: Who is enrolling, who is not and why? Social science \& medicine, 72(2), 157-165. https://doi.org/10.1016/j.socscimed.2010.10.025

Jütting, J. P. (2004). Do community-based health insurance schemes improve poor people's access to health care? Evidence from rural Senegal. World development, 32(2), 273-288. https://doi.org/10.1016/j.worlddev.2003.10.001

Kritz, J. (2018). Building cross-sector collaboration using participatory action research to improve community health in an urban slum in Accra, Ghana. The Lancet Global Health, 6, S38. https://doi.org/10.1016/S2214-109X(18)30167-0

Nolan, B., \& Turbat, V. (1995). Cost recovery in public health services in sub-Saharan Africa. The World Bank. https://doi.org/10.1596/0-8213-3240-6

Nsiah-Boateng, E. (2014). Claims Reimbursement Analysis of the National Health Insurance Scheme in Ghana. Value in Health, 17(7), A432. https://doi.org/10.1016/j.jval.2014.08.1101

Robertson, S. (2001). Health promotion in youth work settings. Health promotion-professional perspectives. 2nd edition. London: Palgrave \& The open university, 169-188. https://doi.org/10.1007/978-1-137-11320-7_15

Seshamani, V. (2016). Faculty of 1000 evaluation for Extending health insurance in Ghana: effects of the National Health Insurance Scheme on maternity care. F1000 - Post-publication peer review of the biomedical literature. Health Policy and Planning, 10(3), 241-256. https://doi.org/10.3410/f.726178773.793514964

Willis, C. Y., \& Leighton, C. (1995). Protecting the poor under cost recovery: the role of means testing. Health policy and planning, 10(3), 241-256. https://doi.org/10.1093/heapol/10.3.241

World Bank. (1988). Financing health services in developing countries : an agenda for reform (English). A World Bank policy study. Washington DC; World Bank. Financing health services in developing countries : an agenda for reform (English) | The World Bank. https://doi.org/10.1596/0-8213-0900-5

World Health Organisation (2009). World health statistics. World Health Organisation, Geneva.

\section{Copyright Disclaimer}

Copyright for this article is retained by the author(s), with first publication rights granted to the journal.

This is an open-access article distributed under the terms and conditions of the Creative Commons Attribution license (http://creativecommons.org/licenses/by/4.0/). 